\title{
Dendritic Calcium Spike Initiation and Repolarization Are Controlled by Distinct Potassium Channel Subtypes in CA1 Pyramidal Neurons
}

\author{
Nace L. Golding, Hae-yoon Jung, Timothy Mickus, and Nelson Spruston \\ Department of Neurobiology and Physiology, Institute for Neuroscience, Northwestern University, Evanston, Illinois 60208
}

In CA1 pyramidal neurons of the hippocampus, calciumdependent spikes occur in vivo during specific behavioral states and may be enhanced during epileptiform activity. However, the mechanisms that control calcium spike initiation and repolarization are poorly understood. Using dendritic and somatic patch-pipette recordings, we show that calcium spikes are initiated in the apical dendrites of CA1 pyramidal neurons and drive bursts of sodium-dependent action potentials at the soma. Initiation of calcium spikes at the soma was suppressed in part by potassium channels activated by sodium-dependent action potentials. Low-threshold, putative D-type potassium channels [blocked by $100 \mu \mathrm{M}$ 4-aminopyridine (4-AP) and 0.5-1 $\mu \mathrm{M} \alpha$-dendrotoxin $(\alpha$-DTX)] played a prominent role in setting a high threshold for somatic calcium spikes, thus restricting ini-

The firing patterns of neurons are determined by the temporal and spatial summation of EPSPs and IPSPs. The influence of these synaptic potentials is determined not only by their electrotonic distance from the site of action potential initiation near the soma but also by their interactions with voltage-gated ion channels. Voltage-gated sodium and calcium channels can be activated by subthreshold EPSPs (Magee et al., 1995), which in turn may affect the magnitude and duration of excitation (Stuart and Sakmann, 1995; Lipowsky et al., 1996; Gillessen and Alzheimer, 1997; Urban et al., 1998; Cash and Yuste, 1999). Furthermore, strong synchronous excitation may generate graded dendritic sodium spikes that influence the triggering of all-or-none action potentials initiated near the soma (Turner et al., 1991; Stuart et al., 1997a; Golding and Spruston, 1998).

In CA1 pyramidal neurons of the hippocampus, complex spikes also can be elicited both in vitro and in vivo. Complex spikes in vitro consist of a series of fast, sodium-dependent action potentials that give rise to a slower calcium-dependent spike (Schwartzkroin and Slawsky, 1977; Wong et al., 1979; Benardo et al., 1982; Andreasen and Lambert, 1995; Miura et al., 1997; Kamondi et al., 1998). Complex spikes in vivo appear to require highly synchronous excitation of presynaptic inputs. They are observed during consummatory behaviors and slow-wave sleep, during which a

Received June 21, 1999; revised Aug. 2, 1999; accepted Aug. 5, 1999.

This work was supported by grants from the National Institutes of Health (NS35180), the Human Frontiers in Science Program, and the Sloan and Klingenstein Foundations (N.S.). N.L.G. was supported by a postdoctoral fellowship from the National Institutes of Health. We thank Nathan Staff for critically reading this manuscript.

Correspondence should be addressed to Nelson Spruston, Department of Neurobiology and Physiology, Northwestern University, 2153 North Campus Drive, Evanston, IL 60208-3520.

Copyright (C) 1999 Society for Neuroscience $\quad 0270-6474 / 99 / 198789-10 \$ 05.00 / 0$ tiation to the dendrites. DTX- and 4-AP-sensitive channels were activated during sodium-dependent action potentials and mediated a large component of their afterhyperpolarization. Once initiated, repetitive firing of calcium spikes was limited by activation of putative BK-type calcium-activated potassium channels (blocked by $250 \mu \mathrm{m}$ tetraethylammonium chloride, $70 \mathrm{~nm}$ charybdotoxin, or $100 \mathrm{~nm}$ iberiotoxin). Thus, the concerted action of calcium- and voltage-activated potassium channels serves to focus spatially and temporally the membrane depolarization and calcium influx generated by calcium spikes during strong, synchronous network excitation.

Key words: bursting; calcium spike; BK channels; dendrotoxin; 4-AP; TEA; hippocampus

large proportion of the hippocampal network discharges in synchrony (Ranck, 1973; Buzsáki et al., 1983; Ylinen et al., 1995; Kamondi et al., 1998). Complex spikes also are prominent during epileptiform activity (Schwartzkroin and Wyler, 1980). The fact that complex spikes are observed both in vitro and in vivo during dendritic recordings but are observed only rarely with somatic recordings under physiological ionic conditions has fueled the assumption that the presumptive underlying calcium spikes are dendritic in origin (Wong et al., 1979; Benardo et al., 1982; Wong and Stewart, 1992; Andreasen and Lambert, 1995; Kamondi et al., 1998).

Why should calcium spikes be initiated in the dendrites and not the somata of CA1 pyramidal neurons? The somata of these cells possess a rich variety of low- and high-voltage-activated calcium channels (Westenbroek et al., 1990, 1992; Hillman et al., 1991; Magee and Johnston, 1995; Talley et al., 1999), with the overall density of calcium channels being approximately comparable along the somatodendritic axis (Magee and Johnston, 1995). Furthermore, dendritic calcium spikes must overcome the repolarizing influence of A-type potassium channels, whose density increases with distance from the soma (Hoffman et al., 1997). In the present study, we used patch-pipette recordings from the soma and apical dendrites of CA1 pyramidal neurons to show directly that calcium spikes are initiated in the dendrites. The restriction of calcium spike initiation to the dendrites is likely the result of strong activation of potassium channels in the soma and proximal dendrites by sodium-dependent action potentials. We show further that different classes of potassium channels regulate different aspects of calcium spikes; putative D-type potassium channels impose on calcium spike initiation a high-activation threshold and dendritic bias, whereas BK-type calcium-activated 
A

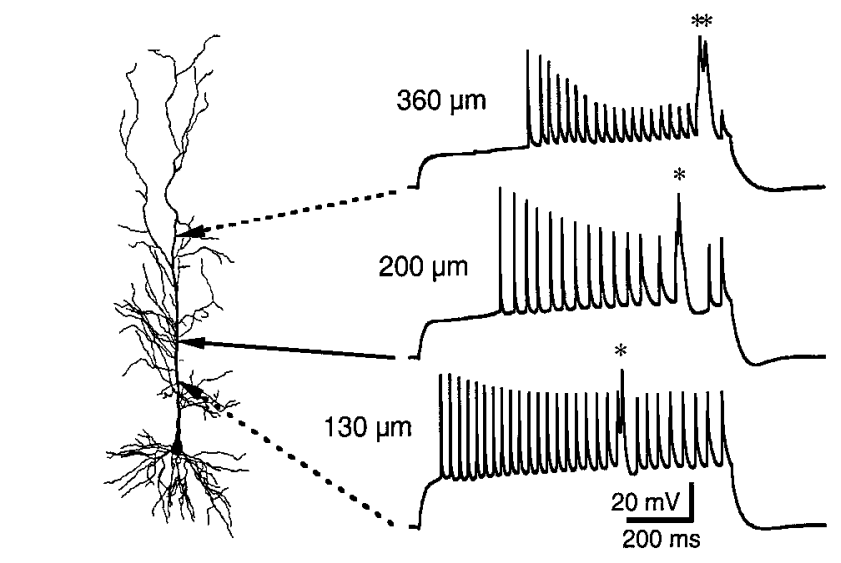

C

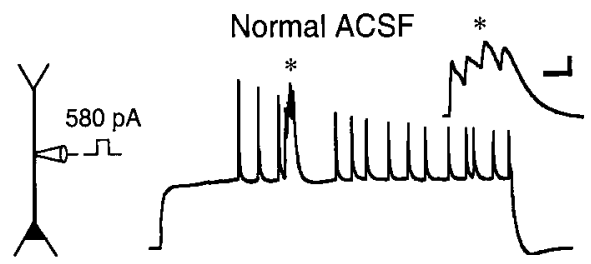

Complex spikes
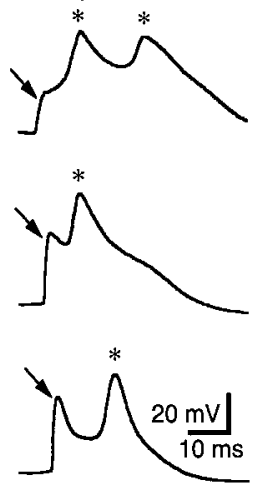

B
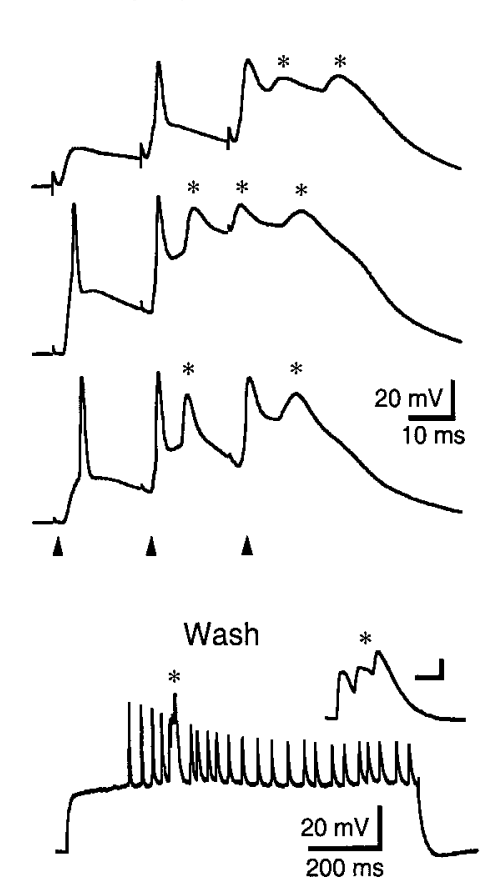

Figure 1. Initiation of calcium spikes. A, Complex spikes detected with dendritic patch-pipette recordings at three different distances from the soma. Each recording is from a different experiment, and the morphological reconstruction is from the recording in the middle panel (200 $\mu \mathrm{m}$ from the soma). In these recordings, fast action potentials decline in amplitude with activity before the generation of a larger amplitude complex spike (asterisks). These complex spikes are shown expanded at the right and consist of an initial small backpropagating action potential (arrows) that gives rise to one to two larger spikes. $B$, Synaptic responses of the same cells shown in $A$ to a train of three shocks (arrowheads) applied to stratum radiatum in the presence of $10 \mu \mathrm{M}$ bicuculline. These stimuli give rise to complex spikes similar to those evoked with dendritic current injection. $C$, The slow component of complex spikes (asterisks) is mediated by calcium channels because it is blocked reversibly by $500 \mu \mathrm{M} \mathrm{Ni}^{2+}$. Dendritic recording $224 \mu \mathrm{m}$ from the soma. Insets show complex spikes expanded in time. Calibration (in insets): $10 \mathrm{mV}, 10 \mathrm{msec}$.

potassium channels curtail the duration of calcium spikes once they are initiated.

\section{MATERIALS AND METHODS}

Slice preparation and maintenance. All electrophysiological recordings were performed using tissue taken from 4- to 8-week-old male Wistar rats. After halothane anesthesia, rats were perfused transcardially with ice-cold oxygenated physiological solution. Hippocampal slices $(300 \mu \mathrm{m})$ were prepared in ice-cold solution using a vibrating tissue slicer (Campden Instruments, Loughborough, UK or Leica, Nussloch, Germany), transferred to an incubation chamber containing warm $\left(35^{\circ} \mathrm{C}\right)$ oxygenated solution for 30-45 min, and then held at room temperature $\left(\sim 24^{\circ} \mathrm{C}\right)$. For recording, slices were transferred to a chamber on the fixed stage of an Axioscop FS microscope (Zeiss, Oberkochen, Germany) and visualized using infrared differential interference videomicroscopy (Stuart et al., 1993). All recordings were performed at $34 \pm 2{ }^{\circ} \mathrm{C}$. The extracellular physiological solution for cardiac perfusion, slice preparation, incubation, and recording contained (in $\mathrm{mM}$ ): $125 \mathrm{NaCl}, 25$ glucose, $25 \mathrm{NaHCO}_{3}, 2.5 \mathrm{KCl}, 1.25 \mathrm{NaH}_{2} \mathrm{PO}_{4}, 2 \mathrm{CaCl}_{2}$, and $1 \mathrm{MgCl}_{2}, \mathrm{pH} 7.4$ (bubbled with $95 \% \mathrm{O}_{2}$ and $5 \% \mathrm{CO}_{2}$ ).

In most experiments, drugs were dissolved in artificial CSF (ACSF) and applied to the bath without interruption of the flow. Tetrodotoxin (TTX), 4-aminopyridine (4-AP), tetraethylammonium chloride (TEA), and charybdotoxin (ChTX) were obtained from Sigma (St. Louis, MO). $\alpha$-Dendrotoxin ( $\alpha$-DTX) and iberiotoxin (IbTX) were obtained from Alomone Labs (Jerusalem, Israel).

In some experiments, $5 \mathrm{mM} \mathrm{NiCl}_{2}$ was dissolved in divalent-free ACSF and applied locally to the soma or apical dendrite using positive pressure applied to the back of a glass pipette (tip diameter of $\sim 20 \mu \mathrm{m}$ ). A dye (0.2\% Fast Green; Sigma) was dissolved in the pipette solution to allow direct visualization of its direction and approximate spread. In every experiment, the flow pattern in the recording chamber was adjusted so that excess local perfusate washed away from the cell (see schematic diagram in Fig. 2).

Current-clamp recordings. Whole-cell recordings were made either from the apical dendrite alone or in conjunction with a second whole-cell recording at the soma. All whole-cell recordings were made with BVC700 amplifiers (Dagan Instruments, Minneapolis, MN) in current-clamp mode, and bridge balance and capacitance compensation were used. Patch electrodes were pulled from thick-walled borosilicate glass (EN-1; Garner Glass, Claremont, CA) and had open tip resistances of 3-11 M $\Omega$ in ACSF. The series resistance ranged between 8 and $50 \mathrm{M} \Omega$ in somatic recordings and between 15 and $80 \mathrm{M} \Omega$ in dendritic recordings (recordings were aborted if the series resistance exceeded $80 \mathrm{M} \Omega$ ). The intracellular solution contained $115 \mathrm{~mm}$ potassium gluconate, $20 \mathrm{~mm} \mathrm{KCl}, 10$ $\mathrm{mm} \mathrm{Na}_{2} \mathrm{PCr}, 10 \mathrm{~mm}$ HEPES, $1 \mathrm{~mm}$ MgATP, $0.3 \mathrm{~mm} \mathrm{Na}_{2} \mathrm{GTP}, 0.1 \%$ biocytin, and either $2 \mathrm{~mm}$ EGTA alone or a combination of $10 \mathrm{~mm}$ EGTA and $0.5 \mathrm{mM} \mathrm{CaCl}_{2}$. Some recordings were obtained using an intracellular solution containing $115 \mathrm{~mm}$ potassium methylsulfate $(n=27)$ instead of potassium gluconate $(n=107)$. Calcium spikes were of similar amplitude and width in gluconate and methylsulfate solutions. However, the number of cells in which calcium spikes were observed was higher in potassium gluconate than potassium methylsulfate, possibly as a consequence of differences in the stability of calcium-activated potassium currents in the presence of these two internal solutions (Zhang et al., 1994).

Electrophysiological data were stored on a Power Macintosh computer system (Apple Computers, Cupertino, CA) via an InstruTech (Port Washington, NY) ITC-16 interface. Stimulus generation and data acquisition were performed using Pulse Control software (R. Bookman, University of Miami, Miami, FL) running under IGOR Pro 3.0 (Wavemetrics, Lake Oswego, OR). Electrophysiological records were filtered at $5 \mathrm{kHz}$ and digitally sampled at $10-50 \mathrm{kHz}$.

Voltage-clamp recordings. Outside-out patches were pulled from the apical dendrites of CA1 pyramidal neurons (56-238 $\mu \mathrm{m}$ from the soma) and held in voltage clamp using either an Axopatch 200A (Axon Instru- 
ments, Foster City, CA) or a PC-ONE (Dagan Instruments) amplifier. Elimination of the capacitance transient was performed on-line using $\mathrm{P}(-4)$ subtraction. Patch electrodes were fabricated with the same glass as in current-clamp experiments and were coated with Sylgard to reduce electrode capacitance. Open tip resistances were 4-10 M $\Omega$ in ACSF. The pipette solution contained (in $\mathrm{mM}$ ): $130 \mathrm{KCl}, 10 \mathrm{Na}_{2} \mathrm{PCr}, 10 \mathrm{HEPES}, 1$ MgATP, $0.3 \mathrm{Na}_{2} \mathrm{GTP}$, and 0.2 EGTA, pH 7.3 with KOH. TTX $(1 \mu \mathrm{M})$ always was included in bath solutions to block sodium currents, and in some experiments, $200 \mu \mathrm{M} \mathrm{Cd}{ }^{2+}$ and $50 \mu \mathrm{M} \mathrm{Ni}^{2+}$ also were included to block calcium currents. Recorded currents were filtered at $1 \mathrm{kHz}$, sampled at $50 \mathrm{kHz}$, and analyzed on computer with IGOR-Pro software. Recorded currents in outside-out patches were averaged from 2-10 trials. Pooled data in whole-cell and outside-out patch recordings are expressed as the mean $\pm \mathrm{SE}$.

Histology. In 29 experiments, cells were morphologically identified by including $0.1 \%$ biocytin in the internal pipette solution. Slices were fixed in $4 \%$ paraformaldehyde and stored refrigerated for up to 2 weeks. Biocytin-filled cells were visualized using the avidin-biotinylated HRP complex reaction (Vectastain ABC Elite kit; Vector Laboratories, Burlingame, CA) using DAB as a chromogen.

\section{RESULTS}

In CA1 pyramidal neurons, depolarizations evoked with steps of current injected through a dendritic recording electrode evoked trains of fast, sodium-dependent action potentials that declined progressively in amplitude (Fig. 1), consistent with previous studies of backpropagating action potentials in these neurons (Callaway and Ross, 1995; Spruston et al., 1995). In $87 \%$ of dendritic recordings, larger depolarizations could also elicit complex spikes consisting of an initial sodium-dependent spike that gave rise to one to three slower and typically larger spikes ( $n=66$ of 76) (Fig. $1 A$ ). When measured, the current threshold for the generation of these complex spikes was generally stable from trial to trial and averaged $572 \pm 28 \mathrm{pA}(n=54)$. Complex spikes could also be elicited synaptically in response to electrical stimulation of stratum radiatum, but only when inhibition was blocked with either 10 $\mu \mathrm{M}$ bicuculline or $50 \mu \mathrm{M}$ SR95531 ( $n=6$ and 3, respectively) (Fig. $1 B)$. Under these conditions, brief trains of synaptic stimuli elicited complex spikes most readily (Fig. $1 B$ ), but in some cases, single stimuli were sufficient. The slower component of complex spikes elicited with current injection was TTX-resistant (data not shown) but was blocked completely at all stimulus strengths by $0.5-1.0 \mathrm{mM} \mathrm{Ni}^{2+}$, indicating that this component was mediated by voltage-gated calcium channels $(n=6)$ (Fig. $1 C)$. Within or above this concentration range, $\mathrm{Ni}^{2+}$ also blocked synaptic transmission, reflecting its nonspecific action on multiple subtypes of calcium channels, including T, R, L, P/Q, and N subtypes (Magee and Johnston, 1995; Zamponi et al., 1996). Complex spikes are thus mediated extensively by an underlying calcium spike.

The site of calcium spike initiation was examined using local application of $\mathrm{Ni}^{2+}$ during single dendritic recordings (Fig. 2). Nickel was dissolved in divalent-free ACSF to $5 \mathrm{~mm}$, included in a glass "puffer" pipette of $\sim 20 \mu \mathrm{m}$ tip diameter, and perfused over restricted regions of the cell by applying positive pressure to the back of the pipette (see Materials and Methods). Although the final concentration of $\mathrm{Ni}^{2+}$ at the cell could not be determined accurately in these experiments, the maximum effective concentration at the cell was probably greater than $0.5 \mathrm{~mm}$, the concentration above which calcium spikes were blocked completely. Local application of $\mathrm{Ni}^{2+}$ to the soma and adjacent dendrites increased reversibly the number and/or width of calcium spikes evoked with dendritic current pulses relative to control $(n=6)$ (Fig. $2 A-C)$. This increased excitability may be explained by a reduction in the activation of calcium-activated potassium channels through blockade of calcium influx by $\mathrm{Ni}^{2+}$.
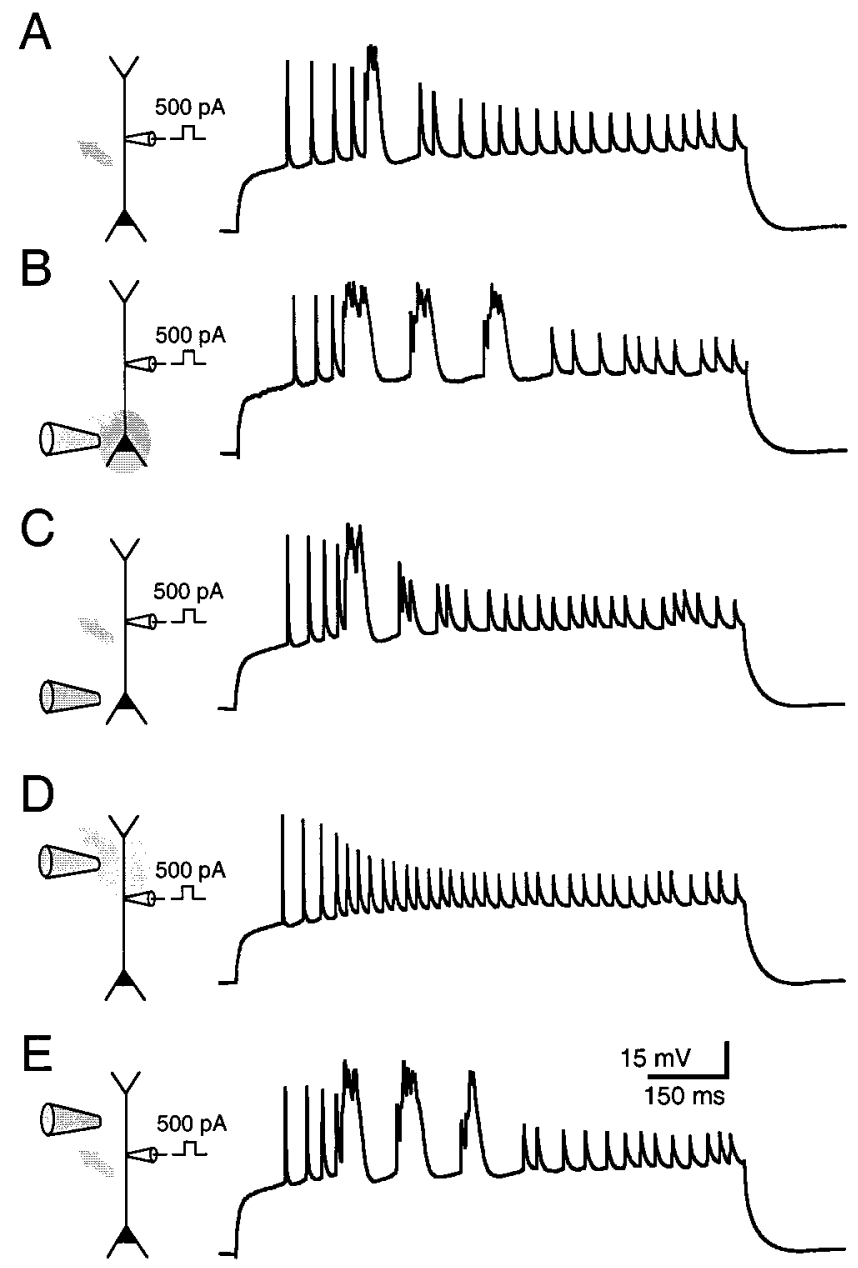

Figure 2. Calcium channel blockade eliminates complex spikes when applied locally to the dendrites but not the soma. $A$, A complex spike was evoked with dendritic current injection (500 pA through a single dendritic patch pipette $220 \mu \mathrm{m}$ from the soma). $B$, Local pressure application of 5 $\mathrm{mM} \mathrm{Ni}{ }^{2+}$ to the somatic region caused repetitive firing of calcium spike bursts and increased the number of individual calcium spikes within a burst. $C$, The effects of $\mathrm{Ni}^{2+}$ were quickly reversed when the pressure application was interrupted. $D, E$, Calcium spikes were eliminated completely and reversibly when $\mathrm{Ni}^{2+}$ was applied to the dendrite, $\sim 100 \mu \mathrm{m}$ distal to the recording pipette. There was an increase in excitability of the neuron upon washout of $\mathrm{Ni}^{2+}$. In schematic illustrations, the area targeted by the local application is indicated by gray ovals, and the direction of the local bath flow is indicated by a gray arrow.

In addition, the result indicates that the lack of calcium spike blockade during somatic $\mathrm{Ni}^{2+}$ application was not caused by the lack of access of $\mathrm{Ni}^{2+}$ to the somatic membrane. In contrast, when $\mathrm{Ni}^{2+}$ was applied to the dendrites $200-400 \mu \mathrm{m}$ from the soma, calcium spikes were blocked completely and reversibly in all trials, even in response to currents of $1-2 \mathrm{nA}(n=5$ of 6 cells; in one cell, calcium spikes could not be blocked by $\mathrm{Ni}^{2+}$ application to either the soma or dendrites, possibly reflecting a technical problem in the delivery of $\mathrm{Ni}^{2+}$ to the cell) (Fig. 2D). These results suggest that calcium spikes are initiated in the dendrites of CA1 pyramidal cells.

Simultaneous patch-pipette recordings were made from the dendrites and somata of CA1 pyramidal neurons to examine further the locus of calcium spike initiation. The threshold for the initiation of calcium spikes differed markedly between the soma and dendrites in physiological saline. Whereas calcium spikes 
A

Figure 3. Threshold for initiation of calcium spikes is lowest in the dendrites. $A$, Patch-pipette recordings made from the soma (thin traces) and apical dendrite (thick traces) $225 \mu \mathrm{m}$ away. A calcium spike (asterisk) was initiated with dendritic current (top pair of traces) but not somatic current injection (bottom pair of traces). The calcium spike is shown expanded in the inset at the right of the top pair of traces. Calibration (in inset): $10 \mathrm{mV}, 20 \mathrm{msec} . B$, In the same cell as in $A$, the disparity between the thresholds of calcium spikes in response to somatic and dendritic current injection was primarily eliminated when action potentials were blocked in the presence of TTX. Isolated calcium spikes are shown expanded at the right of each pair of traces. Calibration (in inset): $10 \mathrm{mV}, 20 \mathrm{msec}$.

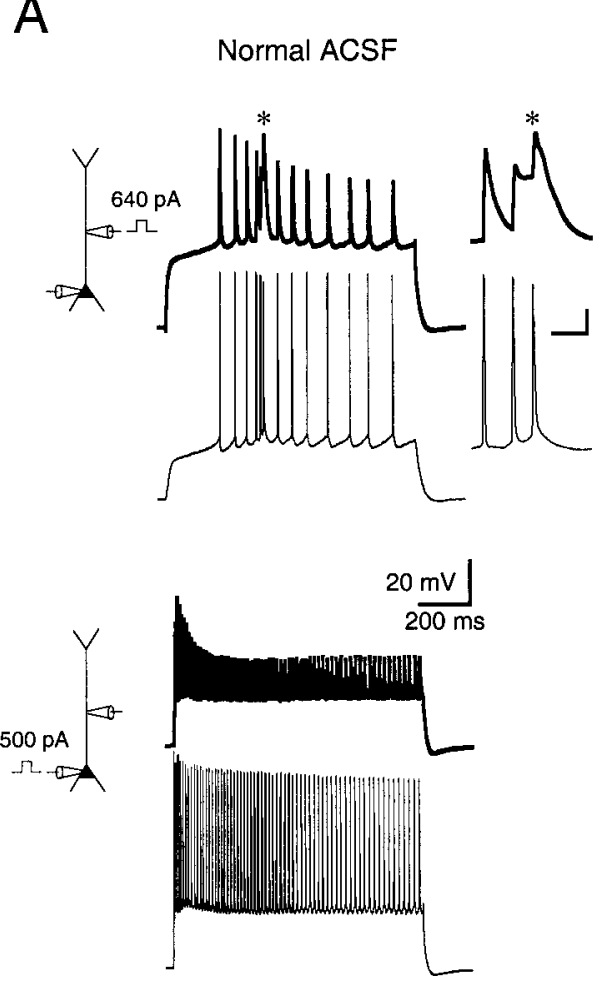

B

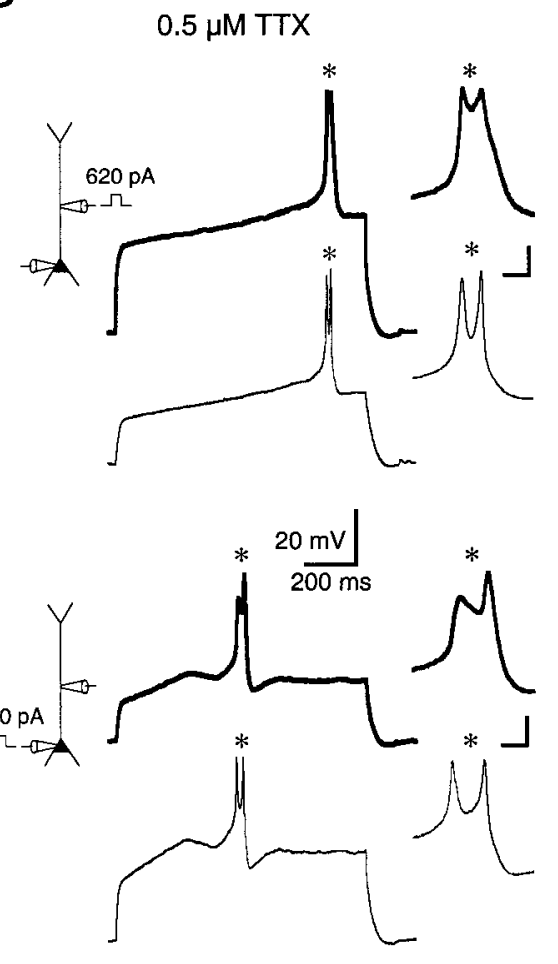

could be elicited with current injected into the dendrites in $87 \%$ of neurons, calcium spikes were elicited in response to somatically injected current pulses of up to $2 \mathrm{nA}$ in only $13 \%$ of neurons in which calcium spikes could be elicited with dendritic current $(n=$ 3 of 24) (Fig. 3A), suggesting that the soma typically does not initiate calcium spikes under physiological ionic conditions. However, the higher threshold for calcium spike initiation at the soma relative to the dendrite was eliminated primarily when sodiumdependent action potentials were blocked with $0.5 \mu \mathrm{M}$ TTX $(n=$ 7 of 10 neurons) (Fig. $3 B$ ). In these seven neurons, not only could calcium spikes be elicited with somatic current injection in the presence of TTX, but the current required for their initiation was only $5 \pm 5 \%$ greater than that required for initiation with dendritic current injection in the same cells (Fig. $3 B$ ).

The above result suggests that sodium-dependent action potentials suppress the initiation of calcium spikes at or near the soma, presumably because of the concomitant activation of potassium conductances. This interpretation rests on the assumption that the site of calcium spike initiation shifts toward the soma in the absence of action potentials. However, the fact that somatic depolarizations may elicit calcium spikes readily in the presence of TTX may reflect the fact that somatic current depolarizes the dendrites more effectively in the absence of sodium-dependent action potentials rather than a shift in the site of initiation per se. To examine this issue, we elicited calcium spikes with somatic current injection in the presence of $0.5 \mu \mathrm{M}$ TTX and locally applied $5 \mathrm{mM} \mathrm{Ni}^{2+}$ to the soma and apical dendrites $(n=4)$ (Fig. 4). Although dendritic applications of $\mathrm{Ni}^{2+}$ raised the current and voltage threshold for calcium spike initiation, they failed in all cases to block calcium spikes entirely (Fig. $4 A, B$ ). In contrast, somatic applications of $\mathrm{Ni}^{2+}$ to the same cells always blocked calcium spikes rapidly and completely (Fig. 4C,D). These results suggest that, in the absence of sodium-dependent action poten- tials, calcium channels near or in the soma underlie a significant component of calcium spikes generated with somatic current.

Both current-clamp and voltage-clamp recordings were used to examine the role of potassium conductances in restricting calcium spike initiation to the dendrites. The threshold for calcium spike initiation was examined with simultaneous somatic and dendritic whole-cell patch-pipette recordings. Whereas in physiological saline calcium spikes could only be initiated with dendritic current injection (Fig. 5A), application of $100 \mu \mathrm{M}$ 4-AP drastically reduced the voltage and current thresholds required to generate calcium spikes, not only in the dendrite, but also in the soma $(n=$ 5 of 7 cells) (Fig. $5 B$ ). The same concentration of 4-AP also reduced the voltage and current threshold for sodium-dependent action potential initiation and reduced the characteristic delay in firing of both action potentials and calcium spikes, even in response to barely suprathreshold depolarizations. The presence of 4-AP did not affect the resting potential of cells significantly but did block the afterhyperpolarization of sodium-dependent action potentials, revealing a prominent afterdepolarization (Fig. $5 A, B)$. Application of 4-AP also consistently reduced the threshold for calcium spike initiation in response to dendritic and somatic current injection in the presence of $0.5 \mu \mathrm{M} \operatorname{TTX}(n=4)$ (data not shown). Together, these results indicate that activation of 4-AP-sensitive potassium currents occurs both below threshold for sodium-dependent action potential generation and during the action potential itself.

The effects of $100 \mu \mathrm{M}$ 4-AP on outward currents elicited in voltage clamp were assessed in outside-out patches pulled from the soma and proximal dendrites (99-238 $\mu \mathrm{m}$ from the soma) of CA1 pyramidal neurons. In physiological saline containing TTX, a voltage command from a holding potential of -80 to $+40 \mathrm{mV}$ activated an outward current that had both transient and steadystate components (Fig. 5C, left). Application of $100 \mu \mathrm{M} 4-\mathrm{AP}$ to 
A

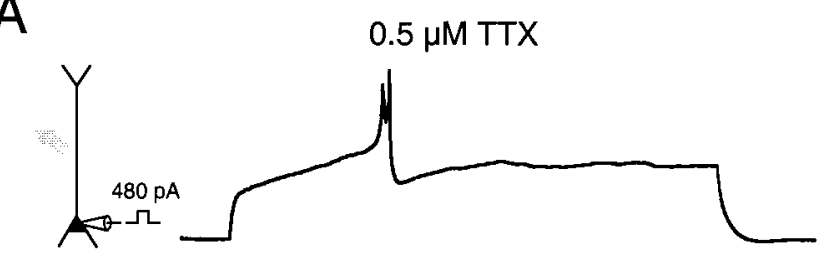

$\mathrm{B}$

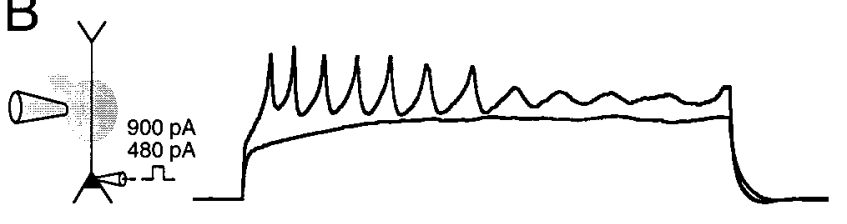

$\mathrm{C}$

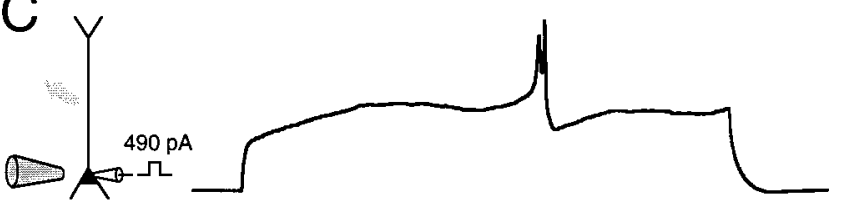

$\mathrm{D}$

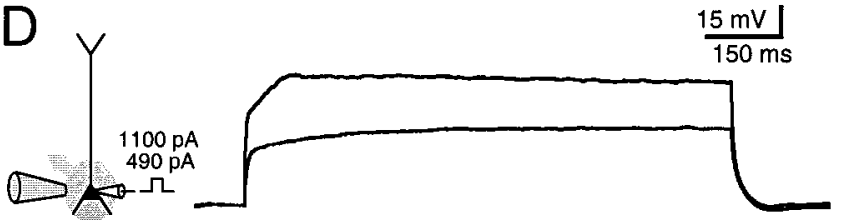

Figure 4. Calcium spikes isolated in the presence of TTX are mediated in part by calcium channels localized near or in the soma. $A$, A presumed calcium spike was initiated with a $480 \mathrm{pA}$ current pulse injected through the somatic patch pipette. $B, C$, Local pressure application of $5 \mathrm{mM} \mathrm{Ni}^{2+}$ raises reversibly the amount of current required to generate calcium spikes. $D$, Calcium spikes were blocked completely, even in response to strong depolarizations, when $\mathrm{Ni}^{2+}$ was applied to the soma and adjacent dendrites. In schematic illustrations, the area targeted by the local application is indicated by gray ovals, and the direction of the local bath flow is indicated by a gray arrow.

the bathing solution reduced the transient component by $19 \%$ $(76.3 \pm 15.3$ to $61.9 \pm 11.3 \mathrm{pA} ; n=10)$ and reduced the steady-state component by $155 \%(8.6 \pm 2.5$ to $-4.7 \pm 2.4 \mathrm{pA} ; n=$ $6)$. The apparent blockade of over $100 \%$ of the steady-state component reflects the fact that 4-AP in many experiments revealed a small inward calcium current. When calcium channels were blocked nonspecifically with $200 \mu \mathrm{M} \mathrm{Cd}{ }^{2+}$ and $50 \mu \mathrm{M} \mathrm{Ni}^{2+}$, $100 \mu \mathrm{M} 4$-AP reduced the transient outward current by $31 \%$ $(108 \pm 31$ to $74 \pm 26 \mathrm{pA} ; n=7)$ and reduced the steady-state component by $98 \%(9.2 \pm 2.3$ to $2.3 \pm 3.7 \mathrm{pA} ; n=5)$. Thus, the blockade of outward currents by 4-AP was primarily insensitive to the activation of calcium channels.

We also examined the effects of $\alpha$-DTX on calcium spike initiation at the soma, because this blocker is thought to act on a similar subset of potassium channels as $100 \mu \mathrm{M} 4-\mathrm{AP}$. Whereas calcium spike initiation was rarely observed in physiological saline, bath application of $0.5-1.0 \mu \mathrm{M} \alpha$-DTX enabled bursts of spikes to be driven with somatic current injection $(n=7$ of 9 cells) (Fig. $6 A$ ), similar to the effects of $100 \mu \mathrm{M} 4$-AP ( $n=5$ of 7 cells) (Fig. $5 A$ ). The average current required for bursts to be elicited was higher in $\alpha$-DTX than in 4-AP (627 vs $426 \mathrm{pA}$ ), possibly reflecting differences in the specificity of the two blockers. DTX-sensitive potassium channels also affected sodiumdependent action potentials in a similar manner as $100 \mu \mathrm{M} 4$-AP (Fig. 6B,C). Both 0.5-1.0 $\mu \mathrm{M}$ DTX and $100 \mu \mathrm{M}$ 4-AP had little effect on the width of action potentials (5 and $6 \%$ average in- crease in DTX and 4-AP; $n=6$ and 9). Rather, the primary effect of both blockers was to reduce the amplitude of the afterhyperpolarization relative to the threshold voltage $(-5.9$ to $2.1 \mathrm{mV}$ in 4-AP; $n=6 ;-4.3$ to $1.0 \mathrm{mV}$ in DTX; $n=9$ ).

The effects of low concentrations of TEA on calcium spikes were distinct from that of 4-AP and $\alpha$-DTX. In current-clamp recordings from the dendrites and somata of CA1 pyramidal neurons, $250 \mu \mathrm{M}$ TEA extended the duration of calcium spike bursts by tens to hundreds of milliseconds but did not affect the resting potential $(n=4)$. A typical example is shown Figure $7 A$. In normal physiological saline, current injected in the dendrite but not the soma of a pyramidal neuron elicited a calcium spike. In the presence of $250 \mu \mathrm{M}$ TEA, the current threshold for calcium spike initiation was reduced only slightly, but the duration of calcium spike bursts increased to several hundred milliseconds. In two of four cells, calcium spikes could be initiated with somatic current injection in the presence of $250 \mu \mathrm{M}$ TEA, but the current threshold in response to somatic injection remained greater than twice the current threshold in response to dendritic injection.

Voltage-clamp analysis of currents from outside-out patches pulled from the proximal dendrites (56-238 $\mu \mathrm{m}$ from the soma) of CA1 pyramidal neurons confirmed that $250 \mu \mathrm{M}$ TEA acted primarily on a calcium-sensitive current (Fig. 7C). Unlike the effects of $100 \mu \mathrm{M}$ 4-AP, $250 \mu \mathrm{M}$ TEA did not affect transient outward currents appreciably but instead blocked a portion of the steady-state current (Fig. 7C, left and inset). TEA reduced the transient current by $7 \%(99 \pm 31$ to $93 \pm 19 \mathrm{pA} ; n=14)$. TEA reduced the steady-state current by $89 \%(15 \pm 5.3$ to $1.7 \pm 2.2$ $\mathrm{pA} ; n=12)$. Also, in contrast to the effects of 4-AP, the blockade of outward current by $250 \mu \mathrm{M}$ TEA was exclusively calciumdependent, because no statistically significant blockade of transient or steady-state currents was observed in patches in the presence of $200 \mu \mathrm{M} \mathrm{Cd}{ }^{2+}$ and $50 \mu \mathrm{M} \mathrm{Ni}^{2+}(n=9$ and 7 , for transient and steady-state components respectively) (Fig. $7 C$, right and inset).

Considered together, the results from the voltage- and currentclamp experiments indicate that $250 \mu \mathrm{M}$ TEA affects primarily calcium-activated potassium channels that in turn contribute to the termination of bursts of calcium spikes. Similar results were obtained with more specific blockers of BK-type calciumactivated potassium channels. In the presence of either $70 \mathrm{~nm}$ $\operatorname{ChTX}(n=4)$ or $100 \mathrm{~nm} \operatorname{IbTX}(n=2)$, the duration of bursts of complex spikes elicited by dendritic current injection increased to several hundred milliseconds (Fig. $8 A, B$ ). These long bursts of complex spikes were calcium-dependent because they were blocked completely and reversibly in the presence of $500 \mu \mathrm{M} \mathrm{Ni}^{2+}$ $(n=3)$ (Fig. 8C,D).

\section{DISCUSSION}

In CA1 pyramidal cells, complex spikes can be generated during behavioral and pathological states that involve highly synchronized activity of the hippocampal network. We find that bursts of sodium-dependent action potentials at the soma are driven by calcium-dependent spikes that are initiated in the apical dendrite. Calcium spike initiation is suppressed at the soma during trains of sodium-dependent action potentials, possibly reflecting activation of voltage-gated potassium channels during action potentials. A presumed D current (see below) plays a critical role in elevating the threshold for calcium spike initiation, particularly in the soma. Once initiated, calcium spikes are terminated in part by the activation of BK-type calcium-dependent potassium channels. The coordinated action of these potassium channels enables cal- 
Figure 5. Potassium channels blocked by low concentrations of 4-AP increase the threshold for calcium spike initiation. $A$, Simultaneous patch-pipette recording from the soma (thin traces) and apical dendrite (thick traces) $160 \mu \mathrm{m}$ away. A calcium spike (asterisk and inset) could be initiated with dendritic current injection (top pair of traces) but not with somatic current injection (bottom pair of traces). $B$, Same recordings as in $A$. Application of $100 \mu \mathrm{M}$ 4-AP drastically reduced the threshold for calcium spike initiation in response to current injection in both the soma and dendrites. Insets show calcium spikes (asterisks) expanded in time. Also note the elimination of the afterhyperpolarization of backpropagating action potentials in 4-AP compared with normal saline. Calibration (in insets): $20 \mathrm{mV}, 10$ msec. $C$, Voltage-clamp recordings from outside-out patches taken from the proximal apical dendrite of pyramidal cells. Left, A voltage command from -80 to $+40 \mathrm{mV}$ evoked both transient and steady-state outward currents in the presence of $1 \mu \mathrm{M}$ TTX (Control). 4-AP $(100 \mu \mathrm{M})$ blocked $\sim 16 \%$ of the fast transient component of the current and eliminated the steady-state component. Right, The effect of $100 \mu \mathrm{M} 4$-AP on outward currents was similar in the presence of calcium channel blockers $\mathrm{Cd}^{2+}(200 \mu \mathrm{M})$ and $\mathrm{Ni}^{2+}(50 \mu \mathrm{M})$. Insets show peak currents (asterisks) expanded in time. Calibration (in insets): $40 \mathrm{pA}, 1$ msec. Thick traces in insets are currents in the 4-AP condition. Patches were pulled from the apical dendrite $140 \mu \mathrm{m}$ (left traces) and $130 \mu \mathrm{m}$ (right traces) from the soma.
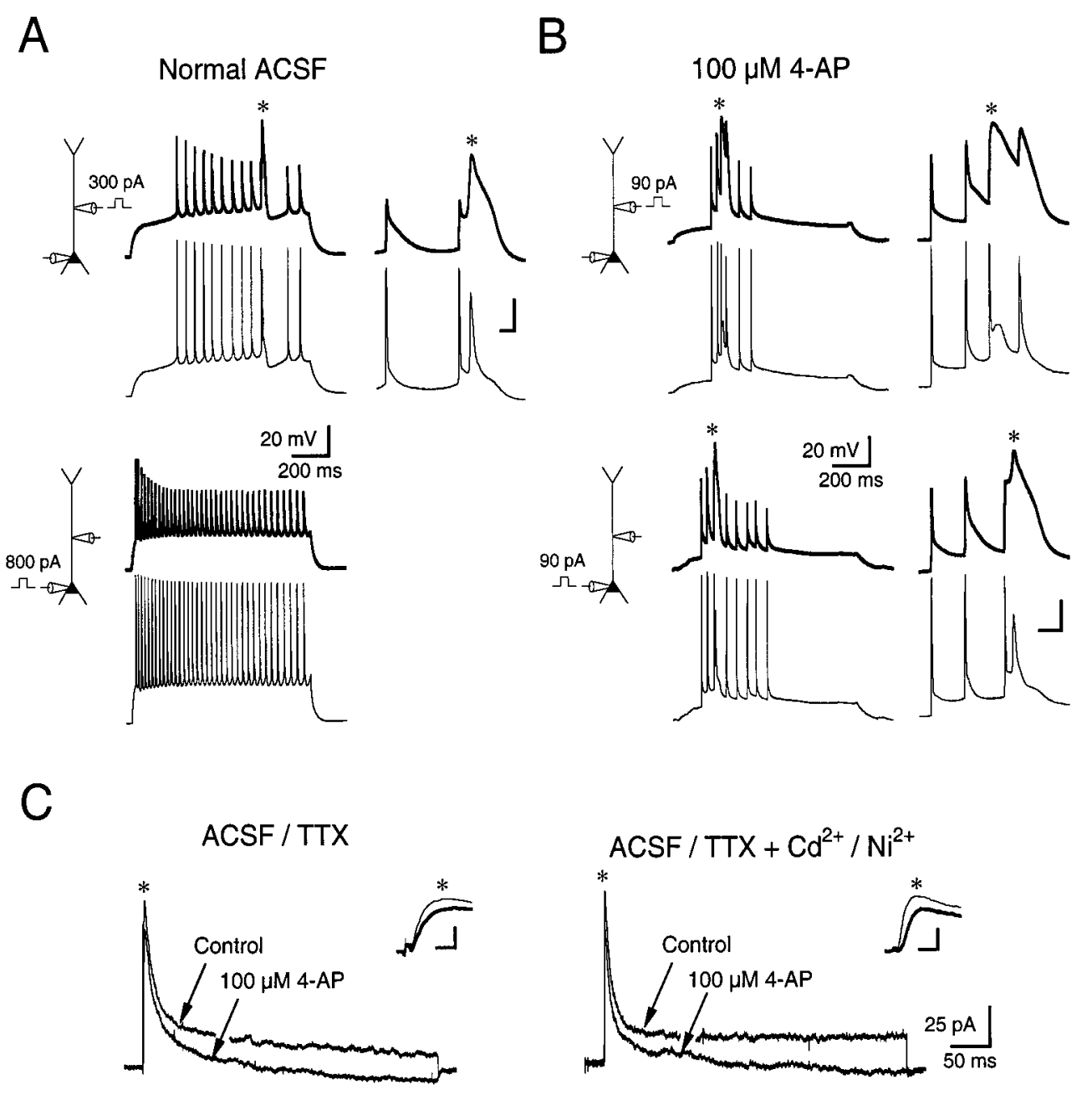

cium spikes to serve as a discrete spatial and temporal cellular signal.

\section{Calcium spikes drive bursts of sodium-dependent action potentials}

In the present experiments, bursts of somatic sodium-dependent action potentials were exclusively associated with dendritic calcium spikes. Furthermore, the duration of action potential bursts followed precisely the changes in the duration of calcium spike bursts induced by blockers of calcium-activated potassium channels. These results show that bursts of sodium-dependent action potentials at the soma are driven by dendritic calcium spikes, as postulated by Traub and Llinás (1979). However, other studies of CA1 pyramidal neurons have concluded that bursts of somatic action potentials can be generated by brief depolarizing stimuli, apparently through a sodium-dependent mechanism (Azouz et al., 1996; Jensen et al., 1996). We have not observed this form of bursting under the experimental conditions of this study, possibly reflecting differences in the recording conditions or slice preparation.

\section{Calcium spikes are initiated in dendrites}

Previous studies using simultaneous somatic and dendritic patchpipette recordings have used the relative timing of sodiumdependent action potentials to determine their site of origin (Stuart et al., 1997b). In the present study, the relative timing of calcium spikes recorded in the soma and dendrites could not be assessed in physiological saline, because their initial rise inevitably was obscured by concurrent sodium-dependent action potentials (Fig. 1A). In the presence of TTX, the timing of calcium spikes also proved to be an unreliable indicator of the site of initiation because of their slow rise times and the lack of a discrete inflection, indicating the beginning of the spike. However, two other lines of evidence indicate that calcium spikes are initiated in the dendrites of CA1 pyramidal neurons. First, the current required for calcium spike initiation was higher at the soma relative to the dendrite. In fact, calcium spikes were rarely observed with somatic current injection, even in response to strong stimuli, in agreement with previous studies using sharp microelectrode recordings (Schwartzkroin and Slawsky, 1977; Wong et al., 1979; Benardo et al., 1982; Wong and Stewart, 1992). Second, calcium spikes were blocked with local dendritic application of $\mathrm{Ni}^{2+}$ at a concentration sufficient to block calcium channels nonspecifically.

Although we could not measure precisely where calcium spikes were initiated in the present experiments, the data suggest that calcium spikes can be initiated in the proximal apical dendrite. Calcium spikes could be initiated with current injection in the apical dendrite at distances as close as $100 \mu \mathrm{m}$ from the soma. The amplitude and shape of calcium spikes elicited with dendritic current injection resembled those elicited with synaptic stimuli during blockade of $\mathrm{GABA}_{\mathrm{A}}$ receptor-mediated inhibition. The initiation of calcium spikes could be blocked consistently with 
A

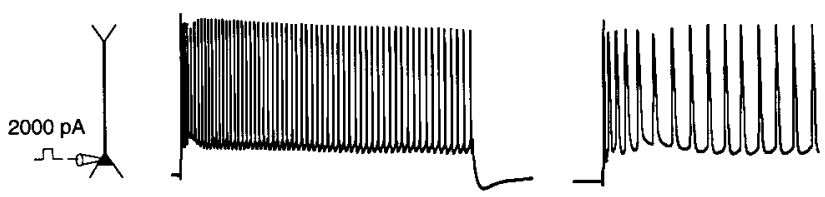

$0.5 \mu \mathrm{M} \mathrm{DTX}$
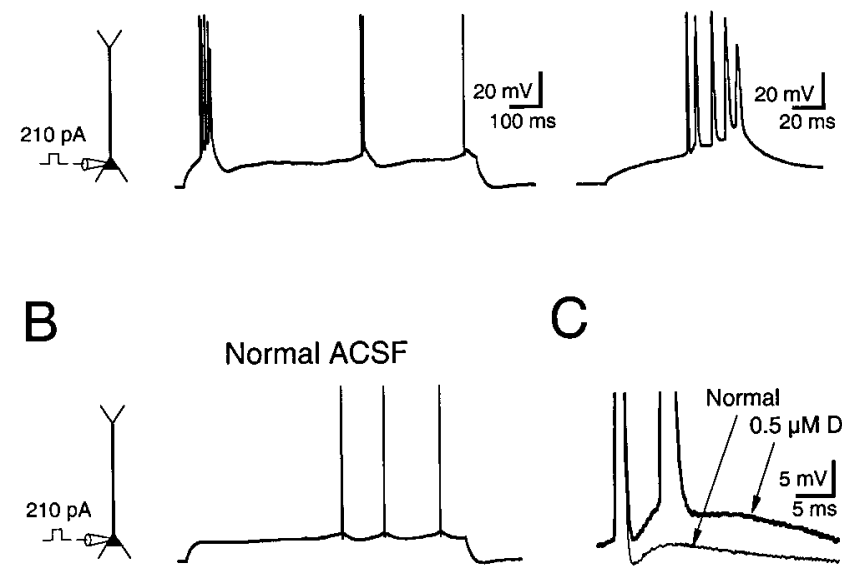

$0.5 \mu \mathrm{M} D T X$

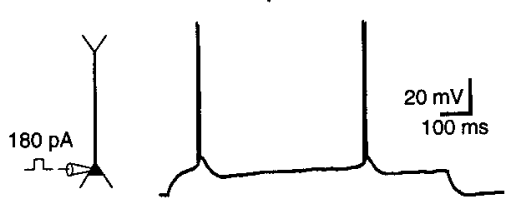

Figure 6. $\alpha$-DTX-sensitive currents suppress calcium spike-driven burst generation at the soma and contribute to the afterhyperpolarization of sodium-dependent action potentials. $A$, In normal saline, bursting was not observed, even in response to a large step of current (top traces). However, the voltage and current thresholds for burst generation markedly decreased in the presence of $0.5 \mu \mathrm{M} \alpha$-DTX (bottom traces). The first 200 msec of responses in each condition are shown expanded at the right. $B$, In the same cell, $\alpha$-DTX reduced the voltage and current threshold for sodium-dependent action potential initiation only slightly and decreased the characteristic delay to firing. $C$, Superposition of the first sodiumdependent action potential in the traces shown in $B$ reveals that $0.5 \mu \mathrm{M}$ $\alpha$-DTX increased the width of the first action potential (measured at half height) by $18 \%$ and reduced the fast afterhyperpolarization by $\sim 3 \mathrm{mV}$ $(82 \%)$. The weakened afterhyperpolarization in the DTX condition led to the generation of a second action potential in close succession to the first.

local application of $\mathrm{Ni}^{2+}$ to the middle third of the apical dendrite $(\sim 200-400 \mu \mathrm{m}$ from the soma). Thus, calcium spikes in CA1 pyramidal neurons, like those in layer V/VI neurons of prefrontal cortex (Seamans et al., 1997), appear to be generated in dendritic regions more proximal to the soma than they do in layer $\mathrm{V}$ neocortical pyramidal neurons in which calcium spikes are initiated preferentially in the distal apical tuft (Amitai et al., 1993; Schiller et al., 1997). However, our data do not exclude the possibility that calcium spikes also may be generated more distally (or in basal dendrites) in response to the appropriate excitatory stimuli.

Sodium-dependent action potentials are elicited at a lower threshold than calcium spikes and play a key role in suppressing calcium spike initiation at the soma. Blockade of action potentials with TTX primarily eliminated the disparity between the current required to initiate calcium spikes in the soma and dendrites. This result explains previous observations that calcium spikes can be elicited in somata when fast sodium-dependent spikes are eliminated (Schwartzkroin and Slawsky, 1977; Benardo et al., 1982; Miura et al., 1997). The higher threshold for somatic calcium spike initiation likely arises from the action potential-induced activation of potassium channels. The relatively strong influence of these channels at the soma relative to the dendrites might reflect a higher somatic channel density or alternatively a stronger activation of channels by backpropagating action potentials. Indeed, action potential amplitude is greatest at the soma and decreases progressively with distance along the apical dendrite, particularly during repetitive firing (Buzsáki et al., 1996; Callaway and Ross, 1995; Spruston et al., 1995; Kamondi et al., 1998). In this manner, action potentials impose on CA1 pyramidal neurons a spatial- and frequency-dependent gradient of potassium channel activation, which would bias calcium spike initiation toward the dendrites.

\section{D-type low-threshold potassium channels control the initiation of calcium spikes}

Voltage-gated potassium channels blocked by $100 \mu \mathrm{M}$ 4-AP and $0.5-1.0 \mu \mathrm{M} \alpha$-DTX raise the threshold for the initiation of calcium spikes in both somata and dendrites. The influence of these channels appears more prominent at the soma, because blockade of these channels with 4-AP or $\alpha$-DTX primarily reduces the difference in threshold for calcium spike initiation between the soma and dendrites. Channels blocked by low 4-AP and $\alpha$-DTX contribute to the delay in firing of sodium-dependent action potentials as well as calcium spikes in response to depolarizing current pulses. These channels also contribute markedly to the afterhyperpolarization of sodium-dependent action potentials and thus provide a long-lasting membrane shunt during trains of action potentials.

The channel type affected by $100 \mu \mathrm{M} 4-\mathrm{AP}$ and $\alpha$-DTX is likely to be a D-type potassium channel, named for its characteristic delaying action on the initiation of action potentials evoked with somatic current injection (Storm, 1988). In CA1 pyramidal neurons, D-type potassium channels activate at negative membrane potentials, inactivate slowly, and are blocked by $100 \mu \mathrm{M} 4-\mathrm{AP}$ as well as submicromolar concentrations of $\alpha$-DTX (Halliwell et al., 1986; Storm, 1988; Wu and Barish, 1992). These findings are consistent with the data from the present study in which $100 \mu \mathrm{M}$ 4-AP blocked primarily a calcium-insensitive steady-state component of outward current in excised patches. The molecular profile of potassium channel subunits that underlie D current is not known precisely. However, given that $\alpha$-DTX blocks with high affinity several $\alpha$ subunit types of the Kv1, Shaker-like potassium channel family (Kv1.1,1.2, and 1.6) (Grissmer et al., 1994; Robertson et al., 1996), it is possible that D current reflects the activation of multiple potassium channel subtypes with overlapping biophysical characteristics.

It has also been proposed that A-type potassium channels play a role in suppressing calcium spike initiation (Hoffman et al., 1997). However, A-type potassium channels activate and inactivate rapidly (within $\sim 50 \mathrm{msec}$ ), making it likely that they contribute only to the initial portion of strong depolarizations. Furthermore, blockade of A current requires millimolar concentrations of 4-AP, which also blocks D current (Storm, 1988; Wu and Barish, 1992; Hoffman et al., 1997). Thus, the extent to which A current influences calcium spike initiation is unclear. 
A

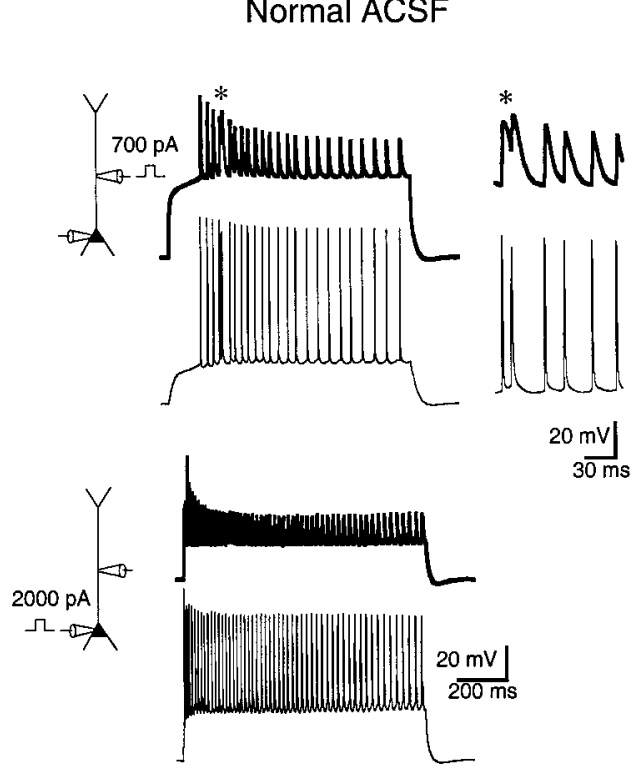

C



B

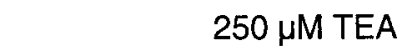

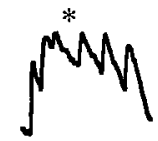

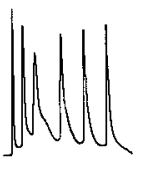

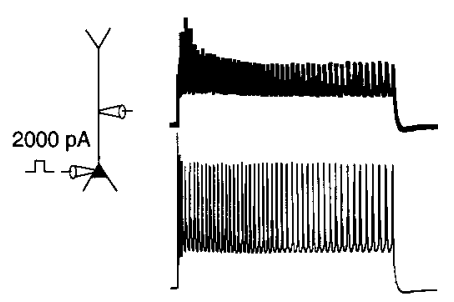

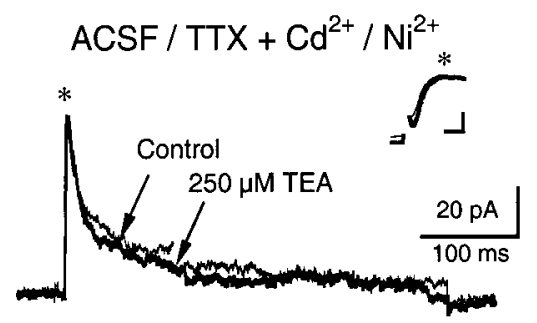

Figure 7. Calcium-activated potassium channels contribute to the repolarization of calcium spike bursts. $A$, Simultaneous patch-pipette recording from the soma (thin traces) and apical dendrite (thick traces) $250 \mu \mathrm{m}$ away. A calcium spike (asterisk and inset) could be initiated with dendritic current injection (top pair of traces) but not with somatic current injection (bottom pair of traces). B, In the same cell, application of $250 \mu \mathrm{M}$ TEA prolonged the burst of dendritic calcium spikes but only reduced slightly the threshold for calcium spike initiation in response to dendritic current injection. Calcium spikes still could not be initiated with somatic current injection in the presence of TEA. Insets show calcium spike bursts (asterisks) expanded in time. $C$, Voltage-clamp recordings from outside-out patches taken from the proximal apical dendrite of CA1 pyramidal cells. Left, A voltage command from - 80 to $+40 \mathrm{mV}$ evoked both transient and steady-state outward currents in the presence of $1 \mu \mathrm{M}$ TTX (Control). TEA (250 $\mu \mathrm{M})$ did not affect the fast transient component of the current but blocked the majority of the steady-state outward current. Right, The effect of TEA was dependent on the activation of calcium channels, because no significant block of outward currents was observed in the presence of Cd ${ }^{2+}(200 \mu \mathrm{M})$ and $\mathrm{Ni}^{2+}(50 \mu \mathrm{M})$. Insets in both left and right panels show peak currents (asterisks) expanded in time. Calibration: left inset, $40 \mathrm{pA}, 1 \mathrm{msec}$; right inset, $20 \mathrm{pA}, 1 \mathrm{msec}$. Thick traces in insets are currents in the TEA condition. Patches were pulled from the apical dendrite $170 \mu \mathrm{m}$ (left traces) and $84 \mu \mathrm{M}$ (right traces) from the soma.

\section{BK-type calcium-activated potassium channels repolarize calcium spikes}

Entry of calcium through voltage-gated channels activates calcium-activated potassium channels, which contribute to the repolarization of somatic sodium-dependent action potentials, underlie different phases of afterhyperpolarizations, and regulate spike frequency accommodation (Lancaster and Nicoll, 1987; Storm, 1987; Sah, 1996; Poolos and Johnston, 1999). Comparatively less is known about how these channels influence the initiation and propagation of calcium spikes. In the present experiments, calcium-dependent currents blocked by $250 \mu \mathrm{M}$ TEA were observed in dendritic patches as far as $238 \mu \mathrm{m}$ from the soma, the most distal recording attempted. Calcium-activated conductances blocked by $250 \mu \mathrm{M}$ TEA, $70 \mathrm{~nm}$ ChTX, and $100 \mathrm{~nm}$ IbTX had only a minor effect on calcium spike initiation threshold but accelerated the repolarization of calcium spikes and suppressed repetitive firing that otherwise could last from tens to hundreds of milliseconds. These effects appear to be mediated primarily by BK-type calcium-activated potassium channels, which are known to be blocked by ChTX and IbTX (Miller et al., 1985; Candia et al., 1992). In contrast to the effects of D-type potassium channels, BK-type calcium-activated potassium channels did not suppress calcium spike initiation at the soma consistently. Thus, BK- and D-type channels provide functionally separate influences on the initiation and termination of calcium spikes.

\section{Role of calcium spikes in neural signaling}

Calcium spikes play an integrative role distinct from sodiumdependent action potentials initiated near the soma. The higher threshold of calcium spikes relative to action potentials confers selectivity to particular combinations of behaviorally relevant stimuli. In the hippocampus, presumed calcium spikes are generated during highly synchronous excitatory input that occurs during sleep and consummatory behaviors (Ranck, 1973; Buzsáki et al., 1983; Kamondi et al., 1998). Calcium spikes in sensory cortical 


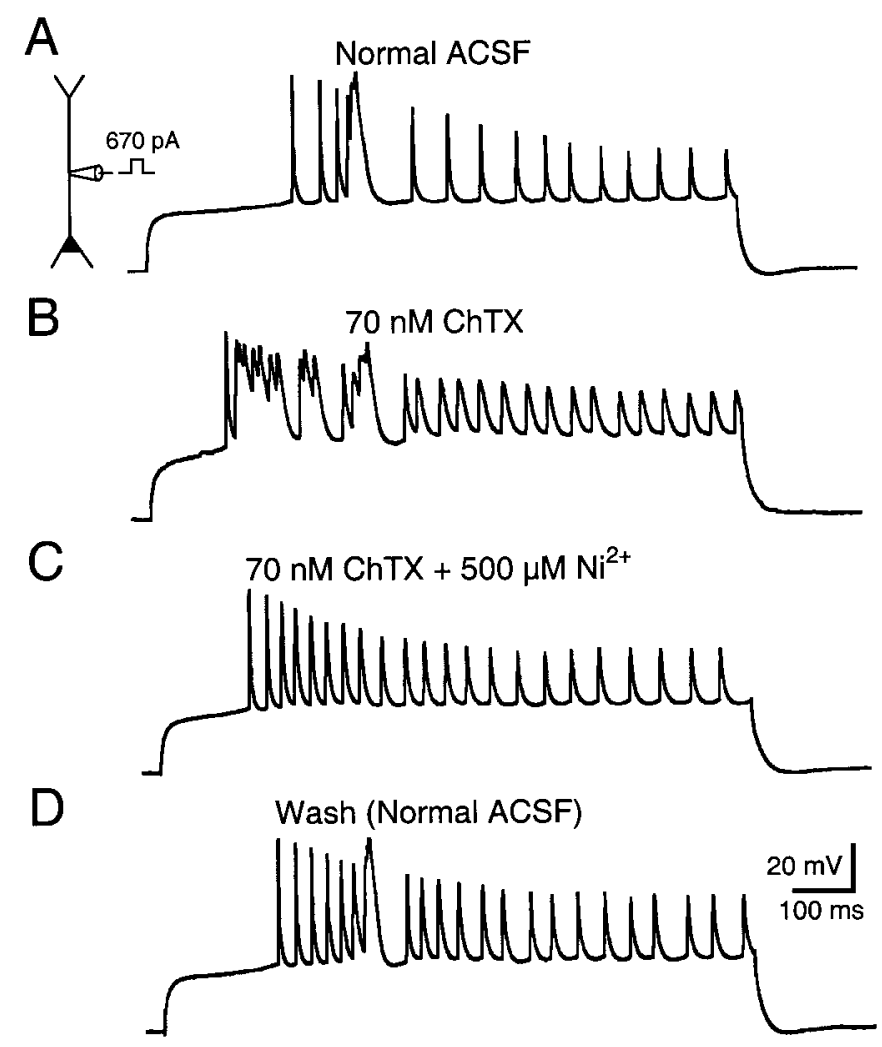

Figure 8. Long bursts of complex spikes evoked in the presence of calcium-activated potassium channel blockers are eliminated by $500 \mu \mathrm{M}$ $\mathrm{Ni}^{2+} . A, \mathrm{~A}$ complex spike was evoked by injecting current through a dendritic recording electrode $225 \mu \mathrm{m}$ from the soma. $B$, Multiple bursts of complex spikes were evoked by the same stimulus in the presence of the 70 nM ChTX. $C, D$, Bursts of complex spikes evoked in the presence of ChTX were blocked reversibly with the addition of $500 \mu \mathrm{M} \mathrm{Ni}{ }^{2}$ to the bath.

neurons can be initiated in response to specific, behaviorally relevant stimuli (Zhu and Connors, 1999). In Purkinje neurons of the cerebellar cortex, calcium spikes are elicited selectively in response to a specific, powerful synaptic input, the climbing fiber, and convey motor information (Eccles et al., 1967; Kitazawa et al., 1998). Thus, in a variety of brain areas, calcium spikes appear to detect specific spatial and temporal combinations of synaptic input and signal these events to the synaptic targets of the neuron through the generation of a distinctive burst of action potential output (Lisman, 1997).

Calcium spikes may serve as powerful regulators of synaptic plasticity, because they would likely mediate a substantial influx of calcium through voltage-gated calcium channels. Furthermore, the prolonged depolarizations mediated by calcium spikes would relieve the voltage-dependent block on NMDA receptors and induce additional calcium influx. Calcium spikes could thus serve as a robust cellular mechanism by which synaptic inputs conveying temporally correlated information might be selectively reinforced. This mechanism would be expected to function effectively in distal dendritic regions in which the influence of backpropagating action potentials is comparatively weak (Spruston et al., 1995; Kamondi et al., 1998).

\section{REFERENCES}

Amitai Y, Friedman A, Connors BW, Gutnick MJ (1993) Regenerative activity in apical dendrites of pyramidal cells in neocortex. Cereb Cortex 3:26-38.
Andreasen M, Lambert JD (1995) Regenerative properties of pyramidal cell dendrites in area CA1 of the rat hippocampus. J Physiol (Lond) 483:421-441.

Azouz R, Jensen MS, Yaari Y (1996) Ionic basis of spike afterdepolarization and bursts generation in adult rat hippocampal CA1 pyramidal cells. J Physiol (Lond) 492:211-223.

Benardo LS, Masukawa LM, Prince DA (1982) Electrophysiology of isolated hippocampal pyramidal dendrites. J Neurosci 2:1614-1622.

Buzsáki G, Leung LW, Vanderwolf CH (1983) Cellular bases of hippocampal EEG in the behaving rat. Brain Res 287:139-171.

Buzsáki G, Penttonen M, Nadasdy Z, Bragin A (1996) Pattern and inhibition-dependent invasion of pyramidal cell dendrites by fast spikes in the hippocampus in vivo. Proc Natl Acad Sci USA 93:9921-9925.

Callaway JC, Ross WN (1995) Frequency-dependent propagation of sodium action potentials in dendrites of hippocampal CA1 pyramidal neurons. J Neurophysiol 74:1395-1403.

Candia S, Garcia ML, Latorre R (1992) Mode of action of iberiotoxin, a potent blocker of the large conductance $\mathrm{Ca}^{2+}$-activated $\mathrm{K}^{+}$channel. Biophys J 63:583-590.

Cash S, Yuste R (1999) Linear summation of excitatory inputs by CA1 pyramidal neurons. Neuron 22:383-394.

Eccles JC, Ito M, Szentagothai J (1967) The cerebellum as a neuronal machine. New York: Springer.

Gillessen T, Alzheimer C (1997) Amplification of EPSPs by low $\mathrm{Ni}^{2+}$ and amiloride-sensitive $\mathrm{Ca}^{2+}$ channels in apical dendrites of rat CA1 pyramidal neurons. J Neurophysiol 77:1639-1643.

Golding NL, Spruston N (1998) Dendritic sodium spikes are variable triggers of axonal action potentials in hippocampal CA1 pyramidal neurons. Neuron 21:1189-1200.

Grissmer S, Nguyen AN, Aiyar J, Hanson DC, Mather RJ, Gutman GA, Karmilowicz MJ, Auperin DD, Chandy KG (1994) Pharmacological characterization of five cloned voltage-gated $\mathrm{K}^{+}$channels, types Kv1.1, $1.2,1.3,1.5$, and 3.1 , stably expressed in mammalian cell lines. Mol Pharmacol 45:1227-1234.

Halliwell JV, Othman IB, Pelchen-Matthews A, Dolly JO (1986) Central action of dendrotoxin: selective reduction of a transient $\mathrm{K}$ conductance in hippocampus and binding to localized acceptors. Proc Natl Acad Sci USA 83:493-497.

Hillman D, Chen S, Aung TT, Cherksey B, Sugimori M, Llinás RR (1991) Localization of P-type calcium channels in the central nervous system. Proc Natl Acad Sci USA 88:7076-7080.

Hoffman DA, Magee JC, Colbert CM, Johnston D (1997) $\mathrm{K}^{+}$channel regulation of signal propagation in dendrites of hippocampal pyramidal neurons. Nature 387:869-875.

Jensen MS, Azouz R, Yaari Y (1996) Spike after-depolarization and burst generation in adult rat hippocampal CA1 pyramidal cells. J Physiol (Lond) 492:199-210.

Kamondi A, Acsady L, Buzsáki G (1998) Dendritic spikes are enhanced by cooperative network activity in the intact hippocampus. J Neurosci 18:3919-3928.

Kitazawa S, Kimura T, Yin PB (1998) Cerebellar complex spikes encode both destinations and errors in arm movements. Nature 392:494-497.

Lancaster B, Nicoll RA (1987) Properties of two calcium-activated hyperpolarizations in rat hippocampal neurones. J Physiol (Lond) 389:187-203.

Lipowsky R, Gillessen T, Alzheimer C (1996) Dendritic $\mathrm{Na}^{+}$channels amplify EPSPs in hippocampal CA1 pyramidal cells. J Neurophysiol 76:2181-2191.

Lisman JE (1997) Bursts as a unit of neural information: making unreliable synapses reliable. Trends Neurosci 20:38-43.

Magee JC, Johnston D (1995) Characterization of single voltage-gated $\mathrm{Na}^{+}$and $\mathrm{Ca}^{2+}$ channels in apical dendrites of rat CA1 pyramidal neurons. J Physiol (Lond) 487:67-90.

Magee JC, Christofi G, Miyakawa H, Christie B, Lasser-Ross N, Johnston D (1995) Subthreshold synaptic activation of voltage-gated $\mathrm{Ca}^{2+}$ channels mediates a localized $\mathrm{Ca}^{2+}$ influx into the dendrites of hippocampal pyramidal neurons. J Neurophysiol 74:1335-1342.

Miller C, Moczydlowski E, Latorre R, Phillips M (1985) Charybdotoxin, a protein inhibitor of single $\mathrm{Ca}^{2+}$-activated $\mathrm{K}^{+}$channels from mammalian skeletal muscle. Nature 313:316-318.

Miura M, Yoshioka M, Miyakawa H, Kato H, Ito KI (1997) Properties of calcium spikes revealed during $\mathrm{GABA}_{\mathrm{A}}$ receptor antagonism in hippocampal CA1 neurons from guinea pigs. J Neurophysiol 78:2269-2279.

Poolos NP, Johnston D (1999) Calcium-activated potassium conduc- 
tances contribute to action potential repolarization at the soma but not the dendrites of hippocampal CA1 pyramidal neurons. J Neurosci 19:5205-5212.

Ranck Jr JB (1973) Studies on single neurons in dorsal hippocampal formation and septum in unrestrained rats. I. Behavioral correlates and firing repertoires. Exp Neurol 41:461-531.

Robertson B, Owen D, Stow J, Butler C, Newland C (1996) Novel effects of dendrotoxin homologues on subtypes of mammalian Kv1 potassium channels expressed in Xenopus oocytes. FEBS Lett 383:26-30.

Sah P (1996) $\mathrm{Ca}^{2+}$-activated $\mathrm{K}^{+}$currents in neurones: types, physiological roles and modulation. Trends Neurosci 19:150-154.

Schiller J, Schiller Y, Stuart G, Sakmann B (1997) Calcium action potentials restricted to distal apical dendrites of rat neocortical pyramidal neurons. J Physiol (Lond) 505:605-616.

Schwartzkroin PA, Slawsky M (1977) Probable calcium spikes in hippocampal neurons. Brain Res 135:157-161.

Schwartzkroin PA, Wyler AR (1980) Mechanisms underlying epileptiform burst discharge. Ann Neurol 7:95-107.

Seamans JK, Gorelova NA, Yang CR (1997) Contributions of voltagegated $\mathrm{Ca}^{2+}$ channels in the proximal versus distal dendrites to synaptic integration in prefrontal cortical neurons. J Neurosci 17:5936-5948.

Spruston N, Schiller Y, Stuart G, Sakmann B (1995) Activity-dependent action potential invasion and calcium influx into hippocampal CA1 dendrites. Science 268:297-300.

Storm JF (1987) Action potential repolarization and a fast afterhyperpolarization in rat hippocampal pyramidal cells. J Physiol (Lond) 385:733-759.

Storm JF (1988) Temporal integration by a slowly inactivating $\mathrm{K}^{+}$current in hippocampal neurons. Nature 336:379-381.

Stuart G, Sakmann B (1995) Amplification of EPSPs by axosomatic sodium channels in neocortical pyramidal neurons. Neuron 15:1065-1076.

Stuart G, Schiller J, Sakmann B (1997a) Action potential initiation and propagation in rat neocortical pyramidal neurons. J Physiol (Lond) 505:617-632.

Stuart G, Spruston N, Sakmann B, Hausser M (1997b) Action potential initiation and backpropagation in neurons of the mammalian CNS. Trends Neurosci 20:125-131.

Stuart GJ, Dodt HU, Sakmann B (1993) Patch-clamp recordings from the soma and dendrites of neurons in brain slices using infrared video microscopy. Pflügers Arch 423:511-518.

Talley EM, Cribbs LL, Lee JH, Daud A, Perez-Reyes E, Bayliss DA
(1999) Differential distribution of three members of a gene family encoding low voltage-activated (T-type) calcium channels. J Neurosci 19:1895-1911.

Traub RD, Llinás R (1979) Hippocampal pyramidal cells: significance of dendritic ionic conductances for neuronal function and epileptogenesis. J Neurophysiol 42:476-496.

Turner RW, Meyers DE, Richardson TL, Barker JL (1991) The site for initiation of action potential discharge over the somatodendritic axis of rat hippocampal CA1 pyramidal neurons. J Neurosci 11:2270-2280.

Urban NN, Henze DA, Barrionuevo G (1998) Amplification of perforant-path EPSPs in CA3 pyramidal cells by LVA calcium and sodium channels. J Neurophysiol 80:1558-1561.

Westenbroek RE, Ahlijanian MK, Catterall WA (1990) Clustering of L-type $\mathrm{Ca}^{2+}$ channels at the base of major dendrites in hippocampal pyramidal neurons. Nature 347:281-284.

Westenbroek RE, Hell JW, Warner C, Dubel SJ, Snutch TP, Catterall WA (1992) Biochemical properties and subcellular distribution of an N-type calcium channel $\alpha 1$ subunit. Neuron 9:1099-1115.

Wong RK, Prince DA, Basbaum AI (1979) Intradendritic recordings from hippocampal neurons. Proc Natl Acad Sci USA 76:986-990.

Wong RKS, Stewart M (1992) Different firing patterns generated in dendrites and somata of CA1 pyramidal neurones in guinea-pig hippocampus. J Physiol (Lond) 457:675-687.

Wu RL, Barish ME (1992) Two pharmacologically and kinetically distinct transient potassium currents in cultured embryonic mouse hippocampal neurons. J Neurosci 12:2235-2246.

Ylinen A, Bragin A, Nadasdy Z, Jando G, Szabo I, Sik A, Buzsáki G (1995) Sharp wave-associated high-frequency oscillation $(200 \mathrm{~Hz})$ in the intact hippocampus: network and intracellular mechanisms. J Neurosci 15:30-46.

Zamponi GW, Bourinet E, Snutch TP (1996) Nickel block of a family of neuronal calcium channels: subtype- and subunit-dependent action at multiple sites. J Membr Biol 151:77-90.

Zhang L, Weiner JL, Valiante TA, Velumian AA, Watson PL, Jahromi SS, Schertzer S, Pennefather P, Carlen PL (1994) Whole-cell recording of the $\mathrm{Ca}^{2+}$-dependent slow afterhyperpolarization in hippocampal neurones: effects of internally applied anions. Pflügers Arch 426:247-253.

Zhu JJ, Connors BW (1999) Intrinsic firing patterns and whisker-evoked synaptic responses of neurons in the rat barrel cortex. J Neurophysiol 81:1171-1183. 